\title{
Survival predictor for penetrating cardiac injury; a 10-year consecutive cohort from a scandinavian trauma center
}

Mari-Liis Kaljusto ${ }^{1,3^{*}}$, Nils Oddvar Skaga ${ }^{2}$, Johan Pillgram-Larsen ${ }^{1}$ and Theis Tønnessen ${ }^{1,3}$

\begin{abstract}
Background: Penetrating cardiac injuries in Europe have been poorly studied. We present a 10-year outcome for patients with penetrating heart injuries at Oslo University Hospital.

Methods: Data from 01.01.2001 until 31.12.2010 was collected from the Oslo University Hospital Trauma Registry and from the patients' records.

Results: Thirty-one patients were admitted with a penetrating cardiac injury. Fourteen patients survived (45\%). Four out of 8 patients (50 \%) with gunshot wounds survived compared to 10 out of 23 (44 \%) with stab wounds. Median (quartiles) for the following values were: Injury Severity Score 25 (21-35), Revised Trauma Score $0(0-6,9)$, Probability of Survival 0,015 (0,004-0,956), Glasgow Coma Scale 3 (3-13). Thirteen patients had signs of life on admission and survived. Eighteen patients were admitted without signs of life and received emergency department thoracotomy. Eight of these had no signs of life at the scene of injury and did not survive. Out of the remaining 10 patients, one survived.

Conclusions: The outcome of patients with penetrating cardiac injury reaching the emergency department with signs of life was excellent. Hemodynamic instability indicates immediate surgery. Stable patients with penetrating thoracic trauma and possible cardiac injury detected by imaging should be considered for conservative treatment.
\end{abstract}

\section{Introduction}

Penetrating cardiac injuries are associated with significant morbidity and mortality [1]. Urgent surgical intervention remains the mainstay of treatment and can be life-saving. Being rare injuries, isolated cardiac penetrations are poorly studied in Europe. In recent years Scottish [2], Dutch [3], Norwegian [4,5], and Icelandic [6] experience with emergency department thoracotomy (EDT) has been published and serves as a source of information for penetrating thoracic and cardiac trauma in these countries. The increasing incidence of violent crime [7] in Oslo, the capital and the largest city in Norway, led us to examine the outcome of the patients with penetrating heart injuries admitted to one of Scandinavia's largest trauma centers,

\footnotetext{
* Correspondence: m.l.kaljusto@gmail.com

'Dept of Cardiothoracic Surgery, Oslo University Hospital, Ullevål, Kirkeveien 166, Postboks 4956 Nydalen, 0424, Oslo, Norway

${ }^{3}$ Hospital, Oslo, Norway and University of Oslo, Oslo, Norway

Full list of author information is available at the end of the article
}

Oslo University Hospital, Ullevål (OUH), in a recent 10year period.

\section{Material and methods}

Population and trauma organization

OUH is a major trauma center admitting nearly 1800 trauma patients annually, of whom $10 \%$ with penetrating injury (Table 1). OUH works along the lines of an American Level I Trauma Center serving the 622000 citizens of Oslo, the "greater Oslo area" of 1,5 million [8] and is a referral trauma center for 2.7 million people in southern Norway. Initial trauma work up is led by a senior resident in general surgery according to the principles of ATLS and the OUH Trauma Manual [9]. The trauma team includes a cardiothoracic resident and both a resident and a consultant in anesthesiology. Immediate EDT is performed on following indications: patients with no signs of life (SOL) on admission who have shown SOL during the transport or on-scene, and exsanguinated patients without immediate response to fluid resuscitation. SOL includes 
Table 1 Primary admissions at Oslo University Hospital Ullevål 2001-2010

\begin{tabular}{lr}
\hline Trauma patients & 7551 \\
\hline Penetrating trauma & 724 \\
Thoracic trauma & 2494 \\
Penetrating thoracic trauma & 261 \\
Penetrating heart injury & 31 \\
\hline
\end{tabular}

spontaneous eye movement, pupillary response, breathing, heart activity, and spontaneous movements. Focused assessment with sonography in trauma (FAST) is a routine part of the initial assessment. Needle pericardiocentesis or subxiphoid pericardial window (SPW) for evacuation of cardiac tamponade has not been practiced in the ED.

\section{Patient selection}

All patients admitted to OUH from 01.01.2001 until 31.12.2010 with penetrating cardiac injury, either isolated or in combination with other injuries, were included. The catchment area was "the greater Oslo-area" while there was a couple of hemodynamically stable patients retrieved from far away distances (the longest distance ca $200 \mathrm{~km})$. Patients transferred from referral hospitals were excluded from the study. The data was extracted from the OUH trauma registry. In addition, the patients' hospital charts were reviewed. The Institutional Data Protection Officer approved the study. The Division of Forensic Medicine and Drug Abuse Research at the Norwegian Institute of Public Health provided the autopsy reports and the total number of deaths caused by penetrating heart injury in the same region during the study period.

Cardiac injury was defined as any injury affecting pericardium and its contents, derived from the registered diagnoses (S26.0 - S26.9, World Health Organization's International Classification of Diseases, ICD-10) [10]). Cardiac injury in conservatively treated patients was diagnosed when pericardial fluid and/or air was present at diagnostic imaging (CT thorax), in addition to a penetrating thoracic injury.

\section{Data collection}

Data obtained included patient age and sex, physiological parameters, SOL on-scene and on admission, Glasgow Coma Scale (GCS), transport time, injury mechanism and location, intraoperative findings, operative procedures, complications, Injury Severity Score (ISS), Revised Trauma Score (RTS), Probability of survival (Ps), the length of hospital stay, neurologic outcome and 30-day survival. The ISS was based on the Abbreviated Injury Scale 1990 Update 98 [11]. Survival status was obtained from the Norwegian Population Registry. Ps was calculated according to Trauma Injury Severity Score (TRISS) methodology [12] with regression coefficients from the US National Trauma Data Bank in 2005.

\section{Statistics}

Statistical analysis was performed using Statistical Package for the Social Sciences (SPSS) v. 16.0 (SPSS Inc, Chicago, IL, USA). Descriptive statistics were calculated for continuous and categorical data and presented as median with range, total numbers and percentage when appropriate. Pvalue $<0.05$ was considered significant.

\section{Results}

Thirty-one patients had penetrating cardiac injury, 14 survived. Epidemiological and clinical characteristics as well as treatment of the patients are presented in Tables 2, 3 and 4 . The total number of deaths from cardiac injury in the same area for the same period was 46 , indicating that 29 patients died on-scene.

Twenty-seven patients arrived by ambulance, three by medevac helicopter and one patient was brought in by the police. The transport time for non-survivors and surgically treated survivors did not differ $(p=0,661)$ (Table 5). Table 5 illustrates median transport time from injury to admission. Thirteen patients out of 31 had SOL on admission and all survived. Eighteen patients were admitted without SOL and underwent EDT. Eight of these did not have SOL on the scene of injury and did not survive. The median GCS was 3, transport time 25 min and ISS 34 . The remaining ten patients had SOL on the scene, but only one of them survived. The time from injury to the EDT for this patient was short, 9 min. The median GCS for the patients with SOL on-scene was 3, transport time 26 min and ISS 26. The patients, who arrived with SOL and underwent surgery, had the median GCS of 9, transport time $21 \mathrm{~min}$ and ISS 25 (Table 5).

There were eight patients with gunshot injuries (26\%) and $23(74 \%)$ with stab wounds. Three patients were injured by a shotgun, pistol and rifle respectively at a long range and received conservative treatment. The projectiles

Table 2 Epidemiological and clinical characteristics of patients with penetrating cardiac injuries

\begin{tabular}{ll}
\hline Variables & Patients $(\mathrm{n}, \%) \mathrm{n}=31$ \\
\hline Male & $26(84 \%)$ \\
Female & $5(16 \%)$ \\
Age & $28^{*}(17-64)$ \\
Violence & 22 \\
Self-inflicted & 6 \\
Unknown & 3 \\
ISS & $25^{*}(21-35)$ \\
RTS & $0^{*}(0-6,9)$ \\
GCS & $3^{*}(3-13)$ \\
PS & $0,0152^{*}(0,004-0,956)$ \\
\hline
\end{tabular}

*denotes median (range)

ISS, Injury Severity Score; RTS, Revised Trauma Score; Ps, Probability of Survival; GCS, Glasgow Coma Scale 
Table 3 Patients' characteristics by type of weapon and wound in terms of survival and treatment

\begin{tabular}{lccccc}
\hline & Total & Survival & EDT & Thoracotomyat OR & Conservative treatment \\
\hline All patients & 31 & 14 & 21 & 3 & 7 \\
SW & 23 & 10 & 16 & 3 & 0 \\
GSW & 8 & 4 & 5 & 9 & 3 \\
Single SW & 13 & 4 & 7 & 0 & 1 \\
Multiple SW & 10 & 6 & 9 & 3 \\
\hline
\end{tabular}

Thoracotomy in OR includes patients which surgical treatment started at the OR

EDT, emergency department thoracotomy; SW, stab wound; GSW, gunshot wound

were embedded in the left ventricular free wall, septum and in the epicardial fatty tissue. Ten patients had multiple stab wounds (Table 3). The left ventricle was injured most frequently, followed by the right ventricle and right atrium (Fig. 1). The exact localization of the injury was unknown for 4 patients treated conservatively. Eight out of 24 patients who underwent surgery had multiple injuries of the heart. AAST-OIS grading system for penetrating cardiac injuries is not yet implemented at $\mathrm{OUH}$.

Twenty-one patients underwent surgery in the ED (Table 3). Two patients completed their surgery in the operating room (OR). Two patients were operated later on the day of admission as the signs of cardiac tamponade were overlooked initially. One patient had a tamponade removed surgically on a subsequent admission one week later - no heart injury was detected at surgery. Another patient was taken directly to the OR for final surgery after drainage of a massive left-sided hemothorax in the ED. He had a large stab wound of the left ventricle and left atrium and was the only patient where cardiopulmonary bypass was used [13]. The outcome was favorable.

Seven stable patients with penetrating thoracic injury presented with intrapericardial fluid or air on CT chest.

Table 4 Treatment, all patients with penetrating cardiac injury $(n=31)$

\begin{tabular}{lc}
\hline Prehospitally & 2 \\
\hline Chest drain & 5 \\
Endotracheal intubation & 11 \\
At ED & $20^{*}(1-10)$ \\
Chest drain & 21 \\
Blood transfusions & 11 \\
ED thoracotomy & 5 \\
Median sternotomy & 5 \\
Anterolateral thoracotomy & 1 \\
Both incisions & 3 \\
Cardiopulmonary bypass & 3 \\
Thoracotomy at OR & Laparotomy
\end{tabular}

*denotes number of patients receiving packed red blood cells (range of amount given from arrival to emergency department (ED) until discharge to ICU or morgue)
Three of them had a low velocity gunshot injury with projectiles embedded in the heart. Interestingly, these patients did not require surgery or drainage of the pericardium. All the hemodynamically stable patients were evaluated by repeated echocardiography and/or CT. Percutaneous pericardial drainage was performed in one patient, followed by a sternotomy for pericardial tamponade one week later.

EDT was performed by the team leader (senior resident in general surgery or board certified general surgeon with no expert competence in cardiothoracic surgery) in three cases with two survivors. The remaining EDT was performed by the resident or consultant in cardiothoracic surgery.

Twelve patients had additional non-thoracic injuries (diaphragm, spleen, liver, pancreas, stomach, small bowel, rectum, kidney, spine, extremities), five of them survived. In non-survivors, the cause of death was heart injury as

Table 5 Patients with penetrating cardiac injuries grouped by signs of life and surgery

\begin{tabular}{|c|c|c|c|c|c|c|}
\hline & & Surgery & $n$ & Median & Range & $M V$ \\
\hline No SOL on-scene & GCS & - & 0 & & & \\
\hline \multirow[t]{5}{*}{$(n=8)$} & & + & 8 & 3 & & \\
\hline & Transport & - & 0 & & & \\
\hline & & + & 7 & 25 & $9-41$ & 1 \\
\hline & ISS & - & 0 & & & \\
\hline & & + & 8 & 34 & $25-75$ & \\
\hline SOL lost in transport & GCS & - & 0 & & & \\
\hline \multirow[t]{5}{*}{$(n=10)$} & & + & 10 & 3 & & \\
\hline & Transport & - & 0 & & & \\
\hline & & + & 8 & 26 & $11-43$ & 2 \\
\hline & ISS & - & 0 & & & \\
\hline & & + & 10 & 26 & $9-75$ & \\
\hline SOL on admission & GCS & - & 7 & 15 & $9-15$ & \\
\hline \multirow[t]{5}{*}{$(n=13)$} & & + & 6 & 9 & $5-15$ & \\
\hline & Transport & - & 6 & 30 & $15-180$ & 1 \\
\hline & & + & 6 & 21 & $15-40$ & \\
\hline & ISS & - & 7 & 21 & $9-22$ & \\
\hline & & + & 6 & 25 & $19-75$ & \\
\hline
\end{tabular}

GCS, Glasgow Coma Scale; ISS, Injury Severity Score; n, number of patients; MV, missing values; SOL, signs of life; Transport, transport time (in minutes) from injury to admission 


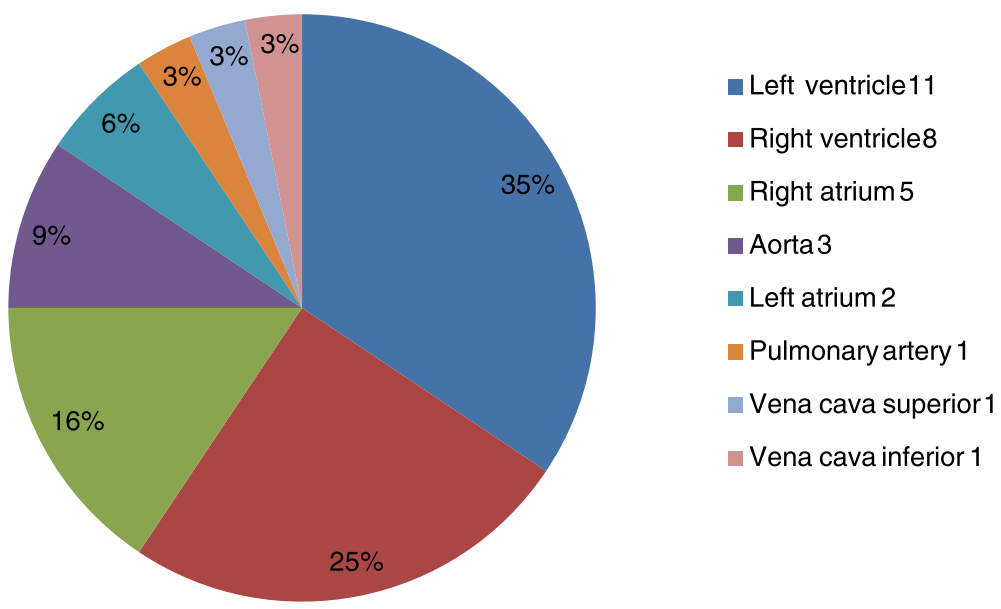

Fig. 1 Total number (legend) and \% (diagram) of the injured cardiac chambers in surgically treated patients

evaluated by the post-mortem examination. One patient underwent a laparotomy concomitantly with EDT with unfavorable outcome. Abdominal surgery was performed in two patients whose heart injury was treated conservatively (Table 4). The median length of stay in the ICU was 2 days (range 1-18), the median hospitalization time 6 days (range $2-18$ ). Nine patients were discharged to the local hospital, one to rehabilitation and four to their home. Two of the survivors suffered from neurologic sequelae; one patient had a paresis of the lower extremity and the other a sensory malfunction of the upper extremity. The latter patient also was stabbed in the neck. One patient was treated for pneumonia. Regarding the long-term follow-up, one patient had the sternotomy wires removed due to discomfort two years after the emergency surgery.

\section{Discussion}

Forty-six persons (76 \%) out of a total of 60 died of penetrating cardiac injury during a ten-year period (2001-2010) in the extended Oslo-area. Thirty-one were brought to OUH and 14 survived. Twenty-four patients underwent surgery, 21 of these EDT. Controversially, half of the survivors were treated conservatively. All patients reaching the hospital with SOL survived. Two patients with signs of cardiac tamponade were misdiagnosed initially and underwent surgery some hours later.

\section{Selection bias and policy of EDT}

Mechanism of injury and physiological status on arrival are the most important determinants of outcome in penetrating cardiac injury, but the outcome is also dependent on the patient selection criteria [14]. In our study, all patients brought to OUH and admitted by the trauma team were included, even patients that in other trauma systems might have been classified as dead on arrival. Approximately $70 \%$ of patients with penetrating cardiac injury die before reaching the hospital $[14,15]$ matching well to our material. There are newer reports presenting similar study size but with a significantly lower mortality indicating that patient selection sometimes is done prehospitally [16-18].

In a previous study of EDT at our center, Pahle et al. [4] found that the time elapsed and SOL were difficult to evaluate in the acute situation. However, the observed $100 \%$ mortality in patients without SOL at the scene of injury justifies a less aggressive approach in this group of patients. Van Waes et al. show $100 \%$ mortality in patients receiving EDT on indication "absence of signs of life" [3]. Rabinovici reports no survivors when EDT is performed on patients without SOL on admission [19]. This is in line with our findings where only one patient out of 18 admitted without SOL survived after EDT.

The ATLS Manual states that if a patient who has sustained a penetrating wound and required cardiopulmonary resuscitation (CPR) in the prehospital setting arrives with no signs of life (reactive pupils, spontaneous movement, or organized ECG activity) to the ED, no further resuscitative effort should be made [20]. In penetrating thoracic trauma cardiac arrest usually occurs due to tamponade or exsanguination [14] and the time to restore blood flow to salvage the brain is approximately 10 minutes [21]. There are no existing guidelines regarding the duration of received CPR, however, CPR given during the transport should be evaluated on the background that closed chest massage with cardiac tamponade is ineffective and in case of exsanguination, pointless [20]. Accordingly, we suggest a flow-chart for penetrating cardiac injuries, also applicable for all penetrating thoracic trauma, on Fig. 2.

\section{Load and go!}

The analysis of the patients' charts leads us to believe that the strategy of "load and go" vs "stay and play" is superior regarding survival. The transport times for operated 


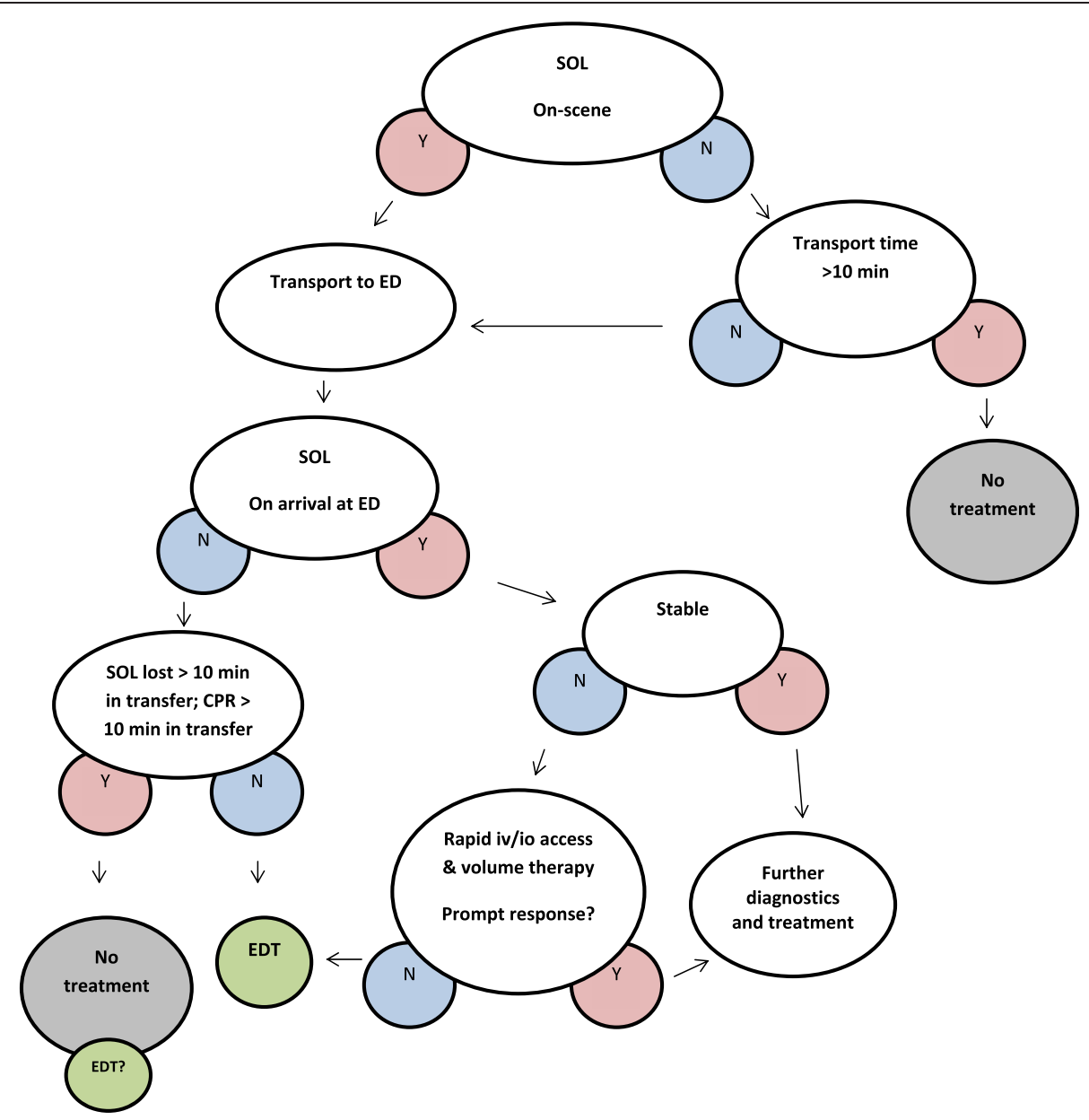

Fig. 2 Proposal for initial management of penetrating cardiac injury on-scene and at the Emergency Department (applicable for all penetrating thoracic injury). CPR, cardiopulmonary resuscitation; EDT, emergency department thoracotomy; iv, intravenous; io, intraosseous; SOL, signs of life

survivors and non-survivors did not differ significantly $(\mathrm{p}=0,661)$, neither did ISS $(\mathrm{p}=0,459)$ indicating that the outcome should be comparable regarding the grade of damage (Table 5). However, based on patients' charts, we believe that the only factors affecting survival in our study were the choice of strategy on the site and transport time.

Prehospital teams might get tangled in resuscitation guidelines including endotracheal intubation, a maneuver that could further aggravate preload in presence of tamponade and delay transport. In our study five patients were intubated prehospitally. Out of these one survived and was treated conservatively indicating a non-dramatic art of his cardiac injury.

\section{Stab wounds vs gunshot wounds}

Exclusion of the three conservatively treated patients reduces the survival in the GSW group to $20 \%$, which is a more likely survival rate for these highly lethal injuries. None of the patients injured by high velocity projectiles had SOL on admission. The only survivor among these happened to shoot himself close to the hospital and was transported to the ED in a few minutes [22].

\section{The role of cardiothoracic surgeon in penetrating cardiac injury}

In 10 years only one patient required the cardiac wound repair assisted by the extracorporeal circuit. However, despite the anecdotic use of cardiopulmonary bypass in our study and studies from larger centers, we still advocate for involving a cardiothoracic surgeon in treatment of penetrating cardiac trauma if possible. These injuries are uncommon, time to surgical treatment is crucial, and the reported mortality is high even in high volume centers [15]. The experience with everyday cardiac surgery is an advantage in managing the technical challenges in these patients and in selected cases, extracorporeal circulation is much helpful [23].

\section{The role of conservative treatment}

We suggest that stable patients with penetrating thoracic injury should undergo thoracic CT. FAST/ echocardiography 
is operator-dependent and might miss a cardiac injury due to a pneumothorax or a lack of tamponade, when the pericardium has been decompressed by blood entering the pleural cavity $[24,25]$. Pericardial fluid or air on CT might indicate cardiac injury and the question of surgery vs conservative treatment arises. Recently Nicol et al. published a randomized controlled study where 55 hemodynamically stable patients with hemopericardium were randomized to sternotomy and 56 patients to SPW with a wash-out and drainage [26]. They concluded the latter treatment to be safe and effective with no increase in mortality and a shorter ICU and hospital stay. SPW was performed under general anaesthesia through a five $\mathrm{cm}$ incision below the sternum. This procedure is less invasive and less traumatic to the patient, but is still to be considered a surgical intervention. Conservative treatment by observation or percutaneous drainage of the pericardium has been reported before [27] and is a safe option for patients with normal physiology as also presented by us. Only one patient, out of seven with conservative treatment, required surgery due to a late tamponade a week after the injury. All the conservatively treated patients were assessed by repeated transthoracic echocardiography (TTE) and/or thoracic CT for evaluation of fluid/ air and rule out valvular injuries. No valvular injuries were detected in this patient group.

Half of the survivors did not require surgery in our patient cohort and the origin and localization of their cardiac injury might seem dubious. We have included pericardium and its contents as the inclusion criteria for cardiac injury, thus it is unknown if all the patients had an injury affecting the surface of the heart itself. Minor lacerations and bleeding of the pericardium, or into the pericardium from the structures around, tend to be self-limiting. These injuries could be managed conservatively or by pericardial drainage similar to the treatment of the iatrogenic cardiac injuries from angiography or pacemaker lab.

\section{In-hospital treatment and follow-up}

Surgically treated patients were followed clinically unless they had a true chamber penetration with possibility of a valvular or septal injury. The latter patients underwent TTE. No valvular or septal pathology was detected. As these patients are usually young and valvular pathology might appear later [28], we suggest echocardiographic follow-up after 1 and 3 years for patients with transmural heart injuries. This was not routinely done in our survivors.

Among the 14 survivors, there was one neurological complication attributable to impaired cerebral blood flow due to either initial cerebral hypoxia or use of extracorporeal bypass. One patient suffered from pneumonia during the hospitalization. Conclusively, the rate of complications was low among the survivors.

\section{Conclusion}

The outcome for patients with penetrating cardiac trauma reaching the ED of OUH alive was excellent. Cardiac arrest more than 10 min away from a trauma center indicates very poor prognosis. Stable patients with penetrating thoracic trauma and possible cardiac injury detected by imaging could be managed conservatively given observation at the ICU and frequent re-imaging. This 10-year survey gives us valuable information to update the Trauma Manual of OUH and change practice regarding patients presenting without SOL on-scene (Fig. 2).

\section{Limitations of the study}

This is a retrospective non-randomized descriptive study with a limited number of patients.

\section{Competing interests}

The authors declare that they have no competing interests.

\section{Authors' contributions}

MLK conceived the study, collected the data, performed the statistical analysis and drafted the manuscript. NOS participated in the design of the study, data collection and drafting the manuscript. JPL contributed to conception of the study, statistical analysis and drafting the manuscript. Tा participated in all of the above-mentioned excluding statistical analysis. All authors have read and approved the final manuscript.

\section{Acknowledgements}

Christina Lyle from the Division of Forensic Medicine and Drug Abuse Research at the Norwegian Institute of Public Health is acknowledged for her contribution.

We thank the trauma registrars Morten Hestnes and Hans Johansson for their continuous efforts at the OUH Trauma Registry.

\section{Author details}

'Dept of Cardiothoracic Surgery, Oslo University Hospital, Ullevål, Kirkeveien 166, Postboks 4956 Nydalen, 0424, Oslo, Norway. ${ }^{2}$ Department of Anesthesiology, Oslo University, Oslo, Norway. ${ }^{3} \mathrm{Hospital}$, Oslo, Norway and University of Oslo, Oslo, Norway.

Received: 11 January 2015 Accepted: 22 May 2015

Published online: 03 June 2015

\section{Reference}

1. Asensio JA, Soto SN, Forno W, Roldan G, Petrone P, Pereira B, et al. Penetrating cardiac injuries: a complex challenge. Injury. 2001;32(7):533-43.

2. Ferris JD, Smith I, Robertson CE. Emergency department at the cutting edge. Eur J Emerg Med. 2008;15(2):67-70.

3. Van Waes OJ, Van Riet PA, Van Lieshout EM, Hartog DD. Immediate thoracotomy for penetrating injuries: ten years' experience at a Dutch level I trauma center. Eur J Trauma Emerg Surg. 2012;38(5):543-51.

4. Pahle AS, Pedersen BL, Skaga NO, Pillgram-Larsen J. Emergency thoracotomy saves lives in a Scandinavian hospital setting. J Trauma. 2010;68(3):599-603.

5. Soreide K, Soiland H, Lossius HM, Vetrhus M, Soreide JA, Soreide E. Resuscitative emergency thoracotomy in a Scandinavian trauma hospital - is it justified? Injury. 2007;38(1):34-42.

6. Johannesdottir BK, Mogensen B, Gudbjartsson T. Emergency thoracotomy as a rescue treatment for trauma patients in Iceland. Injury. 2013;44(9):1186-90.

7. Oslo Politidistrikt. Kriminalitet i Oslo 2012. http://www.politi.no/oslo Accessed 05.09.2014

8. Wikipedia. Den frie encyklopedi. http://no.wikipedia.org/wiki/ Greater_Oslo_Region. 2014. Accessed 05.09.2014

9. Traumemanualen. 6. ed. 2011. Oslo universitetssykehus Ullevål. Avdeling for Traumatologi.

10. WHO. International Classification of Diseases, 10th revision (ICD-10). Geneva: World Health Organization; 1989. http://www.who.int/classifications/icd/en/ Accessed 05.09.2014 
11. Association for the Advancement of Automotive Medicine: The Abbreviated Injury Scale 1990 Revision - Update 98. http://www.trauma.org/archive/ scores/ais.html. Accessed 08.01.2015

12. Boyd CR, Tolson MA, Copes WS. Evaluating trauma care: the TRISS method, Trauma Score and the Injury Severity Score. J Trauma. 1987;27(4):370-8.

13. Kaljusto ML, Tonnessen T. How to mend a broken heart: a major stab wound of the left ventricle. World J Emerg Surg. 2012;7(1):17.

14. Kang N, Hsee L, Rizoli S, Alison P. Penetrating cardiac injury: overcoming the limits set by Nature. Injury. 2009;40(9):919-27.

15. Asensio JA, Berne JD, Demetriades D, Chan L, Murray J, Falabella A, et al. One hundred five penetrating cardiac injuries: a 2-year prospective evaluation. J Trauma. 1998;44(6):1073-82.

16. Pereira BM, Nogueira VB, Calderan TR, Villaca MP, Petrucci O, Fraga GP. Penetrating cardiac trauma: 20-y experience from a university teaching hospital. J Surg Res. 2013;183(2):792-7.

17. Ezzine SB, Bouassida M, Benali M, Ghannouchi M, Chebbi F, Sassi S, et al. Management of penetrating cardiac injuries in the Department of surgery, Mohamed Thahar Maamouri Hospital, Tunisia: report of 19 cases. Pan Afr Med J. 2012;11:54.

18. Janati M, Bolandparvaz S, Salaminia S, Johari HG, Sabet B, Kojuri J. Outcome of penetrating cardiac injuries in southern Iran, Shiraz. Chin J Traumatol. 2013;16(2):89-93.

19. Rabinovici R. Sixty-Seven Consecutive Resuscitative Thoracotomies by A Single Surgeon. Scand J Surg. 2014;103(2):156-60.

20. American College of Surgeons Committee on Trauma. ATLS: Advanced Trauma Life Support for Doctors (Student Course Manual), $8^{\text {th }}$ edition. ISBN-13: 978-1880696316

21. Coats TJ, Keogh S, Clark H, Neal M. Prehospital resuscitative thoracotomy for cardiac arrest after penetrating trauma: rationale and case series. J Trauma. 2001;50(4):670-3.

22. Braathen B, Boen A, Thorsen T, Tonnessen T. Gunshot through the left ventricle. Resuscitation. 2009;80(6):615-6.

23. Chuqhtai TS, Gilardino MS, Fleiszer DM, Evans DC, Brown RA, Mulder DS. An expanding role for cardiopulmonary bypass in trauma. Can J Surg. 2002:45(2):95-103.

24. Cull JD, Bokhari F. Penetrating chest injury in the setting of a hemothorax: should pericardial windows replace echocardiograms? Am Surg. 2013;79(2):E56-7.

25. Nicol AJ, Navsaria PH, Beningfield S, Hommes M, Kahn D. Screening for occult penetrating cardiac injuries. Ann Surg. 2015;261(3):573-8.

26. Nicol AJ, Navsaria PH, Hommes M, Ball CG, Edu S, Kahn D. Sternotomy or drainage for a hemopericardium after penetrating trauma: a randomized controlled study. Ann Surg. 2014;259(3):438-42.

27. Lundy JB, Johnson EK, Seery JM, Pham T, Frizzi JD, Chasen AB. Conservative management of retained cardiac missiles: case report and literature review. J Surg Educ. 2009;66(4):228-35

28. Carr JA, Buterakos R, Bowling WM, Janson L, Kralovich KA, Copeland C, et al. Long-term functional and echocardiographic assessment after penetrating cardiac injury: 5-year follow-up results. J Trauma. 2011;70(3):701-4.

\section{Submit your next manuscript to BioMed Central and take full advantage of:}

- Convenient online submission

- Thorough peer review

- No space constraints or color figure charges

- Immediate publication on acceptance

- Inclusion in PubMed, CAS, Scopus and Google Scholar

- Research which is freely available for redistribution 